\title{
A educação problematizadora de Paulo FREIRE, UMA PEDAGOGIA DO SUJEITO SOCIAL
}

\author{
Sandro de Castro Pitano \\ Universidade Federal de Pelotas (UFPel), Pelotas, Rio Grande do Sul, \\ Brasil
}

\begin{abstract}
Resumo: O artigo apresenta os resultados de uma investigação bibliográfica sobre o pensamento de Paulo Freire, assumindo que o mesmo considera o sujeito social como horizonte formativo. Visa identificar e definir, a partir dos escritos freireanos, um conceito de sujeito social afinado com os princípios políticos e pedagógicos da educação popular. A análise bibliográfica enfatizou as obras: Pedagogia do Oprimido, Conscientização, Pedagogia: Diálogo e Conflito, Política e Educação, Pedagogia da Esperança e Pedagogia da Indignação. Aprofundando o estudo de categorias centrais como conscientização e diálogo, foi possível identificar e caracterizar um conceito de sujeito social na pedagogia freireana, configurando um horizonte formativo em consonância com os fundamentos e ideais da educação popular.

Palavras-Chave: Paulo Freire. Educação Problematizadora. Educação Popular. Sujeito Social.
\end{abstract}

1. INTRODUÇÃO

O texto desenvolve uma análise do pensamento de Paulo Freire, considerando a tese de que o mesmo, assim como a educação popular, tem o sujeito social como horizonte formativo. Almeja definir, a partir da obra freireana, um conceito de sujeito social afinado com princípios políticos e pedagógicos da educação popular, contribuindo para o seu vigor como 
movimento social libertador. Aponta para uma condição humana em construção, emergente da inconclusividade no devir histórico, na qual os sujeitos sejam capazes de assumirem-se como fatores determinantes da existência individual e social

Embora a análise bibliográfica tenha englobado todos os escritos freireanos (livros) acessíveis à pesquisa, dedicou-se maior atenção às obras: Pedagogia do Oprimido, Conscientização, Pedagogia: Diálogo e Conflito, Política e Educação, Pedagogia da Esperança e Pedagogia da Indignação. A escolha resultou da pesquisa exploratória, que permitiu destacá-las em razão de seu potencial sobre a temática do sujeito. Além disso, considerando a amplitude da obra de Freire, seria quase impossível desenvolver o estudo com a profundidade devida sem estabelecer prioridades. E ao estabelecê-las, buscouse selecionar escritos representativos de todos os períodos e características do seu pensamento, razão pela qual a obra dialogada se faz presente.

Como categorias de análise centrais foram assumidas conscientização, incluindo o desdobramento dos diferentes níveis de consciência especificados por Paulo Freire, e o diálogo. O significado de ambas foi evidenciado, buscando demonstrar os nexos estabelecidos ao longo do processo dialético de sistematização do seu pensamento pedagógico e político. A concepção epistemológica afirmada pelo autor é o elemento articulador dos tensionamentos provocados em relação à realidade social, como condição de possibilidade sem a qual o dialético-dialógico resta sem sentido.

O sujeito social é fruto de um caminho de aprendizagem e superação de estágios de consciência. Um caminho jamais linear e, menos ainda, predeterminado. É movimento humano na história de suas relações cada vez mais conscientes com os outros e com o que ocorre no mundo. Embora não seja encontrado, na obra de Freire, o termo sujeito social, o uso de outras expressões com afinidade semântica, tais como sujeito histórico, sujeito da decisão, sujeito cognoscente, sujeito da transformação e sujeito político, revelamno presente, ainda que de maneira implícita.

Considerando apenas as seis obras destacadas nesse estudo, percebese que Freire utiliza o termo sujeito 217 vezes, com diferentes formulações: Conscientização (31) - sujeito da história, sujeito do processo, sujeito conhecedor, ser sujeito; Pedagogia do Oprimido (102) - sujeito dialógico, sujeito da educação, sujeito da transformação, sujeito da história; Pedagogia: diálogo e conflito (03) - sujeito inteligente; Política e educação (29) - sujeito da história, sujeito consciente, sujeito da transformação; Pedagogia da esperança (25) - sujeito histórico, sujeito político, sujeito crítico; Pedagogia da indignação (27) - sujeito ético, sujeito da história, sujeito crítico e sujeito cognoscente. 


\section{A EDUCAÇÃo PROBLEMATIZADORA E SEU HORIZONTE FORMATIVO}

Desde" Educação e Atualidade Brasileira" Freire (2002b) problematiza as condições históricas de opressão e desigualdade social que, fruto das relações colonialistas iniciadas no século XVI, caracterizam o Brasil. Um processo de opressão que, negando a homens e mulheres as condições para assumirem-se como sujeitos de seu próprio mundo, configura uma manifestação de violência. Violência dos opressores, que impede a humanização dos oprimidos. Porém, nessa lógica, os opressores também se desumanizam: assim como aqueles, são homens e mulheres inconclusos, aviltados na busca pelo "ser mais".

A capacidade de dimensionar o tempo, recordar o passado, compreender o presente e planejar o futuro são atributos que o ser humano, inconcluso, foi desenvolvendo. $\mathrm{O}$ inacabamento lhe é característico, porque assim se reconhece através da consciência. E como o ser humano, a realidade que o condiciona também é inacabada. Como processo histórico, ambos se modificam dialeticamente. Em consequência, a realidade muda quando o humano inconcluso a altera por meio da ação, modificando a si mesmo paralelamente. E se para escrever a história o ser humano necessita da "consciência de si", a educação se revela fundamental. Por meio dela é possível viabilizar a superação de posturas deterministas (mecânica) e/ou voluntaristas (idealista) diante da realidade:

Na compreensão da história como possibilidade, o amanhã é problemático. Para que ele venha é preciso que o construamos mediante a transformação do hoje. Há possibilidades para diferentes amanhãs. A luta já não se reduz a retardar o que virá ou a assegurar sua chegada; é preciso reinventar o mundo. A educação é indispensável nessa reinvenção. Assumirmo-nos como sujeitos e objetos da história nos torna seres da decisão, da ruptura. Seres éticos (FREIRE, 2000a, p. 40).

Freire acredita na capacidade que homens e mulheres possuem de superar as suas situações limite, principalmente a exploração historicamente imposta. Transformar a realidade libertando oprimidos e opressores é a preocupação responsável por engendrar a Pedagogia do Oprimido, como pedagogia humanista e libertadora. Ao sistematizar toda a sua obra em prol "da luta constante contra qualquer forma de discriminação", a favor do humanismo, da ética, da bondade, ele se posiciona, claramente, contra "a ordem capitalista vigente que inventou esta aberração: a miséria na fartura" (FREIRE, 1996, p. 115). Comprometendo-se com a transformação da realidade social, desenvolveu a Educação Problematizadora como princípio formativo. 
Segundo Freire (2002b), a alienação resulta da dominação, fazendo do oprimido um ser dual que deseja, não raro, transformar-se em opressor. A alienação representa uma característica histórica da sociedade brasileira, refletindo-se na autodiminuição face às outras pessoas, culturas ou sociedades. O indivíduo alienado vive como um "ser-para-outro" e não como um "ser-para-si". Geralmente, considera a cultura estrangeira melhor, também a moda, a eficiência, mesmo que isto ocorra somente em seu pensamento. Daí que o melhor seja, para os alienados, imitar os valores dos opressores, assumindo-os:

Quando o ser humano pretende imitar a outrem, já não é ele mesmo. Assim também a imitação servil de outras culturas produz uma sociedade alienada ou sociedade-objeto. Quanto mais alguém quer ser outro, tanto menos ele é ele mesmo (FREIRE, 2002d, p. 35).

Se o quadro de "alienação" constatado atrela-se a um problema eminentemente político, cabe contorná-lo pela mesma via. Portanto, política e educação se interligam para atingir um fim comum a todos, o "ser mais". Pela intencionalidade atribuída ao processo educativo, Freire almeja uma educação politicamente definida a favor de um ideal, de um projeto humano sempre em vias de, possibilista diante das contradições sociais impostas e não deterministicamente dadas. Analisando seus escritos e sua trajetória, percebese um defensor ferrenho da justiça social, estimulador da mudança radical, idealista convicto e apaixonado pela liberdade. Entenda-se que a liberdade, para o autor, é um "processo" (FREIRE, 2002g, p. 94), destino "por que temos de brigar incessantemente".

Sobre a organização da sociedade Freire aposta na radicalização da democracia, compreendida para além de uma organização política. Para ele, democracia é um modo de vida, prática constante e construída na relação dialógica com os semelhantes, que passa a ser interiorizada. As pessoas devem envolver-se nos processos formadores da própria história, construindo-a com as próprias mãos. À educação libertadora, o autor adverte que calar diante da exploração que desumaniza é assumir como falso tudo o que foi dito como próprio dos seres humanos frente ao seu contexto; é concordar com os séculos de colonialismo explícito, apoiado na inculcação ideológica de inverdades unilaterais que acabam sedimentadas. E para Freire, as relações dominantes em uma sociedade de classes só podem ser de exploração, dominação e alienação e "se há algo intrinsecamente mau, que deve ser radicalmente transformado e não simplesmente reformado, é o sistema capitalista" (FREIRE, 2002a, p. 69). Por isso, o enfrentamento político e social buscando universalizar o vir-a-ser é o fim maior da sua Educação Problematizadora. 


\section{DiÁlogo E CONSCIENTIZAÇÃO, ALICERCES DO SUJEITO SOCIAL}

Como processo contínuo de desenvolvimento do ser humano, a educação é necessária em sociedade. Possibilita elaborar e modificar comportamentos, podendo ser considerada como fator de mudança. Frente a uma situação social como a brasileira, em que se vive à sombra de um passado autoritário, sem relações dialógicas, "embora não podendo tudo", mas "podendo alguma coisa" (FREIRE, 2002f, p.92), a educação possui fundamental importância. É uma forma de, lentamente, modificar a herança opressiva, que não só os pobres e miseráveis carregam introjetados. Diante disso, a educação que, de acordo com Freire, não é "neutra", precisa posicionar-se entre dois caminhos antagônicos: "uma educação para a domesticação, para a alienação, e uma educação para a liberdade. Educação para o homem-objeto ou educação para o homem-sujeito" (FREIRE, 2002c, p.44).

Convicto de seu posicionamento político e social, "insatisfeito com o mundo de injustiças que está aí" (FREIRE, 2002f, p. 91), o autor opta pelo homem sujeito, horizonte formativo da educação para a liberdade. Uma educação "respeitadora do homem como pessoa" (FREIRE, 2002c, p. 45), única opção a ser seguida por educadores que acreditam no "futuro como possibilidade e não determinismo" (FREIRE, 2002f, p. 92). Se o amanhã fosse um porvir preconcebido, caberia tão somente às pessoas se prepararem para a adaptação. Porém, historicamente, o ser humano não evoluiu ao sabor das circunstâncias, acomodando-se aos reveses da natureza. A acomodação, passiva por sua essência, não é a característica determinante, e sim o oposto, a superação. Superação que se manifesta através da transformação constante e contínua que o ser humano, capaz de produzir, acumular e reproduzir conhecimentos impõe ao espaço.

Essa é a concepção freireana de homem/mulher sujeito, constituindose historicamente. Porém, como um processo dialético, também é possível perceber a sua negação como objetos. A educação para a liberdade busca recuperar a noção de sujeito que, indo além da adaptação, se integra ao contexto. Freire explica que a integração é resultado do ajustamento das pessoas à realidade, acrescida da capacidade de transformá-la, o que a torna mais completa (e mais humana), diferente da simples acomodação/ ajustamento. Daí que, sendo o futuro um tempo a ser construído, exista a necessidade da educação, da formação conjunta das mãos encarregadas de Ihe dar forma:

Quanto mais as pessoas participarem do processo de sua própria educação, maior será sua participação no processo de definir que tipo de produção 
produzir, e para que e por que, e maior será também sua participação no seu próprio desenvolvimento. Quanto mais as pessoas se tornarem elas mesmas, melhor será a democracia. Quanto menos perguntarmos às pessoas o que desejam e a respeito de suas expectativas, menor será a democracia (HORTON; FREIRE, 2003, p. 149).

Formar essas mãos significa possibilitar-lhes a construção das condições físicas e intelectuais para que ajam em seu próprio nome. Para um futuro definido previamente não haveria necessidade de educação, apenas de um processo instrutivo semelhante ao adestramento.

Elemento fundamental da pedagogia freireana é o diálogo, sem o qual não há comunicação. Considerando que o diálogo deve ser desencadeado de modo a se fazer entender por todos os que dialogam, a comunicação se efetua tomando como mediação os problemas locais. Todos precisam se fazer entender por seus pares, para que o coletivo funcione como sociedade. Entretanto, o diálogo somente se constitui quando as pessoas reconhecem o direito que os outros possuem de expor suas ideias e expressar sua opinião. Entre opressor e oprimido não existe diálogo, apenas aquele que comunica ao outro, em uma relação vertical. $O$ processo de comunicação enraizado, estabelecido de cima para baixo, possui existência histórica reconhecida. Portanto, instaurar o diálogo é o ponto de partida para qualquer educação com o povo.

É a partir da ressignificação de sentidos que a ação consciente ganha força - a autorreflexão sobre as contradições do contexto vivencial. Por isso, o conhecimento, em Freire, supera a subjetividade solipsista, já que transcende o paradigma da subjetividade moderna rumo aos sujeitos dialógicos em relação ao objeto do conhecimento. Daí a crítica legítima à prática bancária que, transferidora de saber, é incapaz de promover a conscientização por não problematizar o mundo imediato.

O conhecimento não pode resultar de um ato passivo. $O$ ser humano busca conhecer a partir de suas inquietações, das dúvidas em relação aos problemas que vão surgindo em seu contexto. O conhecimento é entendido pela Educação Problematizadora como um recriar constante, jamais estático (a ideia de que ensinar é transmitir conhecimentos é radicalmente refutada); é resultado da busca determinada, da aplicação da curiosidade sobre o objeto, adquirindo um valor social. Deve pertencer aos homens e às mulheres em geral, servindo para promover o bem comum. Todo conhecimento traz consigo uma mudança na realidade, pois "leva os homens a conhecer que sabem pouco de si mesmos", possibilitando que "ponham a si e seus conhecimentos como problema" (FREIRE, 2001b, p. 95). Problematizando a si e ao mundo é possível haver mudança. 
A concepção problematizadora da educação respeita a natureza do ser humano, percebendo-o como o ser (unicamente) capaz de objetivar o espaço através da práxis - união entre a teoria (pensar) e a prática (agir), construindo sua própria compreensão da realidade. Essa compreensão em permanente processo constitui a consciência, que pode ser tal como a realidade é apresentada. Diante disso, a conscientização representa um aprofundamento da consciência através de um novo processo de apreensão da realidade, em sua relação com o estar sendo daquele que a observa - o sujeito. Isso pode permitir superar o espontaneísmo (passivo) diante dos fatos, contando que são muitos os meios dispostos a trazê-los para todos, através de uma ação mediadora.

Como conhecimento interno, a conscientização possui dois focos de ação: um em relação a si próprio e outro em relação aos outros, considerando todos em seu meio de vida (meio geográfico). A primeira dimensão compreende o sujeito histórico, o "eu no mundo", capaz de trazer a realidade percebida para dentro de si e refleti-la. Por estar voltada para si, nesta dimensão, a conscientização é autoconhecimento. Porém, ele também ocorre na esfera dos outros, do "eu em relação", entendendo-os como semelhantes em sentimentos, necessidades, direitos e deveres na sociedade: é o reconhecimento. Completando o ato de conhecer e reconhecer, a conscientização encontra seu ápice na ação transformadora da realidade.

Concordando com Marx e Engels (2005, p.66), que consideram homens e circunstâncias em movimento permanente e recíproco de construção, é evidenciada a base dialética do processo de libertação. Subjetividade e objetividade passam a ser relacionadas historicamente. Afinal, foram (e continuam sendo) os seres humanos concretos que engendraram a forma histórica de seu próprio mundo, humanizando-o na expressão material e simbólica. $O$ entendimento dessa circunstância é fator de ruptura, motivando o agir consciente, orientado para a assunção do papel de sujeito. Sujeito que, constituído dialogicamente e em contínuo processo de conscientização, identifica-se pelo princípio invariante de que somos todos humanos. Sejamos nós professores, estudantes, pedreiros, pintores, advogados ou desempregados.

O sujeito social, uma vez conceituado, poderá sintetizar com fidelidade e rigor teórico a totalidade dos termos esparsos, porém confluentes, identificados na obra de Freire. Compreender o seu horizonte formativo é fundamental diante de uma realidade injusta, na qual a desigualdade social se reproduz e tende a se perpetuar. Permite problematizar o paradigma cidadão, majoritário no contexto educativo, ao mesmo tempo que robustece a atualidade e a relevância do pensamento de Paulo Freire. É em busca dessa definição que o texto avança. 


\section{O CONCEITO DE SUJEITO SOCIAL EM PAULO FREIRE}

Ao longo das páginas anteriores, discorreu-se sobre a concepção pedagógica libertadora de Paulo Freire, assentada nos pilares do diálogo e da conscientização. Ensaiou-se uma aproximação ao sujeito social, inerente às formulações freireanas sobre a existência humana. Agora a análise será aprofundada em direção ao horizonte formativo da educação popular, estabelecendo a pertinência do referido conceito no e a partir do pensamento de Freire. Entende-se fundamental a superação do modelo cidadão, moldado pela democracia capitalista e assumido pela educação em geral, e mesmo com ressalvas, pela educação popular. É o que mostram estudos como o de Pitano (2016) amparado em análise documental e em clássicos sobre a cidadania como Cortina (1997) e Marshall (1967).

As categorias conscientização e diálogo continuarão tendo papel fundamental nessa reflexão, cujo intuito é demonstrar que o sujeito social corresponde ao construto-horizonte do pensamento de Freire, em afinidade com o projeto político da educação popular. $O$ vigor teórico e prático de ambas no pensamento freireano e seu possível impacto na educação popular justifica que lhes seja dedicada especial ênfase.

$\mathrm{Na}$ tentativa de caracterizar e conceituar o sujeito social no pensamento de Freire, o ponto de partida é a sua visão de mundo como processo. O nascimento representa a gênese de uma unicidade histórica que encarna, concomitantemente, a singularidade em formação e a socialização do indivíduo, ambas relacionadas no interior do processo vivencial. Desde então, tem lugar a inserção em um complexo sistema de objetos existentes e organizados, relações e contradições com as quais o indivíduo vai se familiarizando. O adentramento dinâmico vai construindo, através das mediações, a individualidade, que engendra, nesse movimento, concepções de mundo. Tais concepções sofrem influências diversas e decorrem de vários fatores. Porém, a determinação maior se deve à interação entre consciência e mundo, quando subjetividade e objetividade interagem com os elementos materiais e simbólicos disponíveis em determinado espaço e tempo.

A consciência ganha espaço na análise da existência humana como uma atividade individual, mediada pela realidade, que opera uma compreensão do que se passa ao redor. Em um primeiro momento, o "eu" pode ser apontado como centralidade diante do real objetivado, configurando algo como um "discurso interior" (BAKHTIN, 2006, p. 118). Porém, mesmo construída na interioridade individual, a consciência como discurso interior jamais seria viável sem condições advindas do exterior. O processo de sua 
formação é inerente às relações entre subjetividade e objetividade. E a formação depende das influências diretas da situação social no contexto imediato à existência individual. Em um movimento complexo, o indivíduo, encharcado de experiências históricas, efetua um trabalho de apreensão do contexto. Traduz e reconstrói, através de sua estrutura biológica e cognitiva, os estímulos recebidos do exterior, como um processo de construção do conhecimento. De fato, é possível compreender a consciência como um conhecimento dos fatos, das coisas, complementado pela capacidade reflexiva, o reconhecimento.

Reconhecer as condições da existência exige o desenvolvimento de atividades analíticas e sintéticas, como uma tradução imediata que se aprofunda. Reside no simbólico a possibilidade do sujeito, compreendendo as relações que o circundam, efetuar essa reconstrução compreensiva, de maneira mais ou menos fiel ao fenômeno analisado. Segundo Bakhtin (2006, p. 32), "um signo não existe apenas como parte de uma realidade", pois ele também "pode distorcer essa realidade, ser-lhe fiel, ou apreendê-la de um ponto de vista específico". A consciência somente se constitui pela assimilação e tratamento do conteúdo que lhe é apresentado em forma de signos. É na interação social que a consciência, impregnando-se de conteúdos simbólicos, constitui-se na interioridade do eu.

A consciência individual "não só nada pode explicar, mas, do contrário, deve ela própria ser explicada a partir do meio ideológico e social. A consciência individual é um fato socioideológico" (BAKHTIN, 2006, p. 35). A elaboração de si e do mundo na interioridade da consciência, no discurso interior, demonstra o nexo com a afirmação do eu como sujeito, inseparável da afirmação em ato com o mundo. É quando tem lugar a conscientização, exigência efetiva do movimento de libertação e de construção do sujeito social em Freire.

Na vida cotidiana, o poder ideológico se consolida discursivamente com facilidade, graças ao espontaneísmo com o qual se movem os sujeitos. Heller (2004, p. 17) salienta que "a vida cotidiana é a vida de todo homem", todos vivenciam o seu dia a dia ingênuo, o seu cotidiano. Porém, embora assimile a todos, nenhum indivíduo vive tão somente absorto na cotidianidade. A questão basilar é que, mesmo não homogeneizando a inserção no cotidiano, trata-se de um fato inconteste a pertença a ele desde os primórdios da existência individual: "o fato de se nascer já lançado na cotidianidade continua significando que os homens assumem como dadas as funções da vida cotidiana" (HELLER, 2004, p.17). Assim, seria possível conceber uma unidade imediata de pensamento e ação, negando a práxis como afastamento crítico entre consciência e mundo. 
Para Freire (1980, p. 26), a conscientização"implica que os homens assumam o papel de sujeitos que fazem e refazem" as condições de sua existência. Ela compartilha algumas características do sujeito, ambos são processos, inacabados, históricos e expostos às contingências. As contradições se abrigam na barreira constituída de situações limites, compostas por uma esfera concreta e outra imaginária, em permanente contato. A concreta corresponde ao fenômeno em curso, por exemplo, a fome. Trata-se de um obstáculo a ser vencido e todos são sabedores disso. Solucionar o problema da fome parece ser uma tarefa simples em um mundo que produz alimento para ser transformado em combustível. Porém, talvez implicasse em uma ruptura profunda demais no sistema de produção e consumo dominante e acaba se perpetuando.

As situações limite, de acordo com Freire (1980, p. 30), "implicam na existência de pessoas que são servidas direta ou indiretamente por estas situações, e outras para as quais elas possuem um caráter negativo e domesticado". No exemplo da fome, a parcela das pessoas domesticadas não corresponde apenas às que sofrem na pele a sua crueldade, mas, também, àquelas que restam chocadas com o sofrimento das vítimas. Como se trata de um fenômeno de grande proporção, sua existência depende do convencimento de uma ampla parte da sociedade mundial, perfazendo a dimensão necessária para erguer a barreira correspondente. Portanto, o processo de enfrentamento a ser empreendido, precisa focar, além do problema concreto, a maneira como ele é percebido, ou seja, a dimensão imaginária.

Freire entende que o mundo é uma construção histórica do trabalho humano linguisticamente constituído, desde a compreensão necessária entre os interlocutores até a internalização da exterioridade em construção. Tudo isso se desdobra em novas ações externas, através da atividade constituidora de sentidos. Buscando promover uma apreensão menos espontânea do mundo, aponta o caminho da compreensão simbólica, possibilitada pelo afastamento da realidade e pelo incentivo à atividade crítica da consciência em relação a ela:

Sem dúvida, quando os homens percebem a realidade como densa, impenetrável e envolvente, é indispensável proceder a esta procura por meio da abstração. Este método não implica que se deva reduzir o concreto ao abstrato (o que significaria que o método não é do tipo dialético), mas que se mantenham os dois elementos, como contrários, em inter-relação dialética no ato de reflexão (FREIRE, 1980, p. 30-31). 
Essa compreensão conduz ao processo de codificação e decodificação da situação existencial enfocada como problema, situação limite cuja superação depende da práxis humana. Codificar uma dada situação corresponde à maneira pela qual é possível efetuar o distanciamento crítico da vida cotidiana em seu conjunto de contradições. Partindo da codificação, o processo impulsiona o exercício da consciência com relação à exterioridade, por meio da significação. Freire utiliza a fotografia, o desenho e o slide como instrumentos de expressão da realidade codificada. Diante deles, os sujeitos admiram o próprio contexto, tornando-se, neste ato, ativos observadores da situação em que vivem, objetivando-a. A meta é permitir que a realidade seja percebida como um desafio a ser enfrentado e superado, e não mais uma barreira intransponível.

A decodificação busca possibilitar que uma postura crítica seja assumida sobre o contexto imediato. Viabilizando, por meio da relação dialética entre realidade objetiva e subjetividade reflexiva, novas formas de ação que ponham em curso o processo de libertação. Sem refletir criticamente o ser humano não chega a ser sujeito. Em Freire, vir a ser sujeito é parte do processo educacional, tal como uma aprendizagem permanente. A atuação em níveis mais críticos sobre a realidade não provoca apenas a mudança das relações objetivas, mas, também, do indivíduo atuante. A identificação das situações limite, por meio da decodificação, é atividade primordial para o engajamento concreto pela transformação, pois não é possível combater o indiscernível.

Transformar as relações sociais opressoras é fundamento e horizonte do processo de libertação. A transformação, do latim transformatio-onis (CUNHA, 2007, p. 782), diferentemente da reforma, contempla uma mudança profunda que envolve forma e conteúdo. Transformar é criar o novo, atitude de quem nega o que está sendo e assume a utopia possível, por exemplo, um mundo sem fome. Seu enfoque é a materialidade necessária, ao abordar a dureza da desigualdade e da opressão negadoras da vida, cuja solução revelase impossível por dentro da lógica vigente. É dessa percepção que se nutre a transformação anunciadora da utopia: viver sob uma legalidade ilegítima, romper um contrato em que os oprimidos ficam apartados no momento de serem compostas as cláusulas. O legítimo é o que está por vir, promovendo a identificação com o legal (legitimidade = legalidade).

Sem transformação, as estruturas continuam idênticas e o máximo alcançado poderá ser uma inversão de papéis entre opressores e oprimidos. A meta é superar, completamente, a contradição opressor-oprimido já que, ao mantê-la, existirão emancipações localizadas, nunca a libertação, que consiste no surgimento do homem novo: 
É pois essencial que os oprimidos levem a termo um combate que resolva a contradição em que estão presos, e a contradição não será resolvida senão pela aparição de um "homem novo": nem opressor, nem oprimido, mas um homem em fase de libertação. Se a finalidade dos oprimidos é chegar a ser plenamente humanos, não a alcançarão contentando-se em inverter os termos da contradição, mudando somente os polos (FREIRE, 1980, p. 59).

Nessa trajetória paralela entre mudança dos seres humanos e mudança do mundo, Freire enfatiza a existência de níveis de consciência que podem e devem ser superados no curso de uma educação libertadora.

No primeiro nível está a consciência semi-intransitiva, caracterizada pela imersão quase total na realidade. A percepção sobre os desafios é deturpada, completamente determinada pela manipulação ideológica. A vida cotidiana envolve a capacidade de compreensão dos problemas, pois não consegue transbordar os limites da própria experiência. Como explica Freire (1980, p. 67), os indivíduos cuja consciência está situada nesse nível, "carecem do que chamamos 'percepção estrutural', a qual se faz e se refaz a partir da realidade concreta, na apreensão da problemática". Não conseguem provocar mudanças significativas em sua condição vivencial, em razão de não a refletirem criticamente, não a reelaborarem. Até a problematizam, porém, limitados pela imersão em que se encontram, acabam, com frequência, atribuindo a causa das contradições a forças superiores (Deus), ou mesmo a si próprios.

A ampliação da capacidade de diálogo com os outros e com o mundo, acompanhada de uma maior captação da esfera existencial, abre espaço para a transitivação da consciência. A dialogicidade é o resultado permanente do processo de troca recíproca, intersubjetiva, em um movimento de "sair-desi" em direção a si mesmo, ao outro e ao mundo. Não é um movimento de disputa argumentativa, cujo convencimento é a meta, e sim uma contribuição ao crescimento coletivo que caracteriza a essência, nunca uma estratégia de convivência. É por isso que, em meio a sociedade opressora, o diálogo tende a ser atrofiado e até impossibilitado, pois os princípios da igualdade e ausência de domínio que o caracterizam em relação recíproca dos participantes inexistem. Há sempre a dependência, o domínio, o jogo de interesses e necessidades que o impedem de efetivar-se.

Como expressão comunicativa entre os sujeitos, o diálogo representa a essência da interlocução entre homens e mulheres diferentes, respeitosa da abertura para o mundo. Comprometido com a libertação, o diálogo compreende a "crítica da negatividade material roubada" (DUSSEL, 2000, p. 427), almejando atingir, coletivamente, não a consciência da opressão, 
mas a sua ilegítima razão de ser. É um encontro simétrico e intencional, não importando se entre indivíduos iguais ou desiguais socialmente, que ensina, na prática, serem as desigualdades inconcebíveis, em virtude da condição humana que nos assemelha e identifica como diferentes. Mais que emancipar, pela superação e melhora qualitativa de estágios cognitivos, o diálogo freireano é libertador, gerando uma sabedoria revolucionária capaz de fundar um novo sujeito.

Freire se refere ao espaço urbano para evidenciar o primeiro nível da consciência transitiva, a transitivo-ingênua. Embora mais aberta diante do mundo do que a consciência intransitiva, essa ainda "se caracteriza, entre outros aspectos, pela simplicidade na interpretação dos problemas" (FREIRE, 2002c, p. 68). O indivíduo ainda não efetua um afastamento suficiente em relação ao contexto, para que possa refletir, criticamente, sobre os condicionantes impostos. Continua dominado pela ideologia opressora e a transitividade se resume a acompanhar as mudanças operadas pelo próprio sistema político e econômico.

Todo esse processo seria impensável sem a ação educativa, cuja tarefa é se constituir em vetor de formas mais radicais de participação teórica e prática, almejando um nível mais profundo de percepção dos fatos. A alfabetização, por exemplo, pode assumir diferentes perspectivas de ação, dependendo da visão de mundo daqueles que a coordenam. Na perspectiva conservadora, os analfabetos são indivíduos marginalizados e inferiores que precisam ser incluídos no estilo de vida dominante. Os educadores são agentes de inclusão, imbuídos de emancipar os marginalizados de sua condição, excessivamente, inferior - uma espécie de salvação dos excluídos, para que possam participar (passivamente) da dinâmica social que se moderniza a cada dia. Programas de alfabetização com tais características nunca almejam a libertação, somente a emancipação, pois "nunca colocarão em questão a própria realidade" em suas contradições insolúveis (Freire, 1980, p. 75). A contradição opressor-oprimido não pode ser superada nesse panorama, no qual os oprimidos são mantidos como seres para o outro. Portanto, a forma conservadora de alfabetizar visa incluir e emancipar (no sentido de elevar de posição dentro do sistema) e o processo de alfabetização tende a reforçar o caráter fechado do contexto vital.

Já na perspectiva libertadora, em que os analfabetos são considerados como oprimidos pelo sistema, a educação assume a tarefa de constituir sujeitos sociais. Suas características, em conexão com a visão de mundo que sustenta, assim a revelam. A não neutralidade de uma educação comprometida com a práxis libertadora funda-se no entendimento de que não há conciliação possível entre a libertação e a lógica das relações oriundas 
do sistema capitalista. É nesse sentido que a libertação se consolida na obra freireana como vocação e horizonte na busca pelo ser mais.

Antagônicas aos interesses opressores, Educação Problematizadora e educação popular se caracterizam como questionadoras, dialógicas, libertadoras e, consequentemente, revolucionárias. Fundamentadas no diálogo como forma de comunicação, almejam atingir o terceiro nível da consciência, a transitivo-crítica ou consciência crítica. A explicação de Freire (2002c, p. 69) é contundente:

A transitividade crítica, por outro lado, a que chegaríamos com uma educação dialogal e ativa voltada para a responsabilidade social e política, se caracteriza pela profundidade na interpretação dos problemas [...] pela recusa a posições quietistas [...] pela prática do diálogo [...] por se inclinar sempre a arguições.

Se a elevação da consciência intransitiva ao nível da transitividade ingênua corresponde ao acompanhamento e à adesão às mudanças de teor econômico no contexto, o mesmo não ocorre com a sua superação pela consciência crítica. Ela começa a ser alcançada apenas quando a percepção dos fatos é aprofundada através da reflexão crítica. As relações causais transcendem explicações superficiais que levam ao imobilismo, por serem consideradas inerentes, naturais ou fruto da vontade divina. Ação e reflexão se unem na práxis, uma vez que, em uma reflexão crítica, tende a suceder uma ação igualmente crítica, isto é, uma ação que corresponda à condição dos oprimidos não mais como seres para o outro, e sim como seres com o outro e para si, sujeitos sociais. A "ultrapassagem do estado de objetos para o de sujeitos", afirma Freire (2002e, p. 127), "não pode prescindir nem da ação das massas, nem de sua reflexão", autêntica práxis libertadora.

Avançar sozinho é buscar apenas a emancipação, assumindo o individualismo sistêmico. A plenitude da existência, embora sempre se fazendo, consiste em poder pronunciar o mundo, atitude do sujeito que transforma o meio em que vive. Por isso, a dimensão coletiva se revela um imperativo, uma vez que "dizer a palavra não é privilégio de alguns homens, mas direito de todos" (FREIRE, 2002e, p. 78). É impossível pronunciar o mundo sozinho, da mesma forma que tornar-se sujeito quando apartado dos outros, pois como salienta Geraldi (2006, p. 19), "a língua e os sujeitos se constituem nos processos interativos". O sujeito, assim, se constitui pela interação com os demais e com a sua consciência. A horizontalidade do diálogo estabelece relações de confiança e reconhecimento, verdadeira comunhão no processo esperançoso de vir a ser mais. Por isso, o diálogo compõe um dos princípios basilares do processo de constituição do sujeito social. 
A relação dialógica permite romper a tradição autoritária, pois problematiza razões de ser e as desvela, evidenciando bases de sustentação em sua fragilidade diante do conhecimento crítico. Ao mostrar a legitimidade de outra maneira de se relacionar com os outros, o diálogo provoca o tensionamento das relações de opressão, impulsionando o sujeito a realizar sua vocação de ser mais.

\section{CONSIDERAÇÕES FINAIS}

Como visto, em Freire, a prática de uma educação crítica e dialógica viabiliza um processo de conscientização social e política capaz de conduzir os sujeitos à práxis libertadora. Essas características ratificam, ao mesmo tempo, a pertinência do pensamento freireano às condições de vida em sociedades oprimidas e a atualidade de sua pedagogia. Nessas circunstâncias marcadas pela cultura do silêncio, condição de mutismo das gentes que condiciona o estar sendo pelo antidiálogo, a instauração do processo de conscientização é imperativo existencial. Consequentemente, constituir o sujeito social implica na gênese conflituosa, em meio à luta em torno da transformação material das relações sociais. É, ao mesmo tempo, uma luta pedagógica e política.

Somente por meio da transformação podem ser gestadas ações que materializem as condições possíveis, nas quais os seres humanos possam se constituir como sujeitos sociais. Sujeitos emergentes da inconclusividade no devir histórico, capazes de assumirem-se fatores determinantes da existência individual e social; sujeitos que participam e interferem, efetiva e criticamente nos acontecimentos do contexto, com os outros sujeitos, reconhecidos na figura do nós. Afinal, como atesta Freire (In: TORRES, 2001, p. 52), "não é o eu, não é o 'eu existo,' 'eu penso', que explica o 'eu existo'. É o 'nós pensamos' que explica o 'eu penso'. Não é o 'eu sei' que explica o'nós sabemos'. É o’nós sabemos' que explica o'eu sei"'.

Ao radicalizar os atributos do cidadão, negando a reforma e afirmando a transformação do sistema capitalista, o sujeito social corresponde ao conceito efetivamente afinado com os princípios e horizontes da educação popular. Enquanto ao cidadão cabe respeitar as leis do estado democrático, criadas e aprovadas por seus representantes, o sujeito social, imbuído de uma concepção bem mais ampla de participação política, não se contenta em ser agente passivo na sociedade.

O sujeito social concebido pela Educação Problematizadora, coerente com os fundamentos e objetivos da educação popular, assume o destino de "criar e transformar o mundo, sendo sujeito de sua ação" (FREIRE, 2002d, p. 38). Segundo Freire (2001c, p. 94) o ser humano se autentica como sujeito, 
singularmente diferente em relação aos demais, porém igual no princípio determinante de ser ativo e capaz de conquistar a transformação política e social. E o sujeito dessa conquista é o sujeito social, o homem novo, cuja postura ativa e dialógica revela suas origens enraizadas no processo de libertação. Que encontra fundamento e autenticidade no movimento de vir a ser, marca da incompletude de quem se constrói com os outros, no movimento histórico de busca pela humanização solidária de todos.

Artigo recebido em: 19/10/2016

Aprovado para publicação em: 13/12/2016

THE PROBLEMATIZING EDUCATION OF PAULO FREIRE,A PEDAGOGY OF THE SOCIAL SUBJECT

ABSTRACT: The article presents the results of a bibliographical study on the thought of Paulo Freire, based on the assumption that he considers the social subject as an educational/formative horizon. It aims at identifying and defining, from Freire's writings, a concept of social subject in tune with the political and pedagogical principles of popular education. The bibliographical analysis emphasized the following works: Pedagogy of the Oppressed, Conscientization, Education: Dialogue and Conflict, Politics and Education, Pedagogy of Hope and Pedagogy of Indignation. By deepening the study of core categories such as awareness and dialogue, it was possible to identify and characterize a concept of social subject in Freire's pedagogy, setting an educational/ formative horizon in line with the foundations and ideals of popular education.

KeYwords: Paulo Freire. Problem-posing Education. Popular Education. Social Subject.

\section{LA EDUCACIÓN PROBLEMATIZADORA DE PAULO FREIRE, UNA PEDAGOGÍA DEL SUJETO SOCIAL}

RESUMEN: El artículo presenta los resultados de una investigación bibliográfica sobre el pensamiento de Paulo Freire, asumiendo que considera al sujeto social como siendo um horizonte formativo. Su objetivo es identificar y definir, a partir de los escritos de Freire, un concepto de sujeto social en sintonía con los principios políticos y pedagógicos de la educación popular. En la revisión de la literatura se enfatizaron las obras: Pedagogía del Oprimido, Concienciación, Pedagogía: Diálogo y Conflicto, Política y Educación, Pedagogía de la Esperanza y Pedagogía de la Indignación. Con la profundización del estudio de las categorías centrales, tales como concienciación 
y diálogo, fue posible identificar y caracterizar un concepto de sujeto social en la pedagogía de Freire, estableciendo un horizonte formativo en sintonía con los fundamentos e ideales de la educación popular.

Palabras Clave: Paulo Freire. Educación Problematizadora. Educación Popular. Sujeto Social.

\section{REFERÊNCIAS}

BAKHTIN, M. Marxismo e filosofia da linguagem. 12. ed. Trad. Michel Lahud e Yara Vieira. São Paulo: Hucitec, 2006.

CORTINA, A. Ciudadanos del Mundo:hacia una teoría de la ciudadanía. Madrid: Alianza, 1997.

CUNHA, A. G. Dicionário etimológico da língua portuguesa. 3. ed. Rio de Janeiro: Lexikon, 2007.

DUSSEL, E. Ética da libertação: na idade da globalização e da exclusão. Tradução Ephraim Alves e Lucia Orth. Petrópolis, RJ: Vozes, 2000.

FREIRE, P. Conscientização: teoria e prática da libertação. São Paulo: Moraes, 1980. . Pedagogia: diálogo e conflito. São Paulo: Cortez, 1985. . Pedagogia da Autonomia: saberes necessários à prática educativa. São Paulo: Paz e Terra, 1996. . À Sombra desta Mangueira. São Paulo: Olho d'Água, 2000a. Unesp, 2000b. . Política e Educação: ensaios. São Paulo: Cortez, 2001a. .Pedagogia dos sonhos possíveis. In:. FREIRE, A. M. A. (Org.). São Paulo: Editora UNESP, $2001 \mathrm{~b}$. . Ação Cultural para a Liberdade. São Paulo: Paz e Terra, 2002a. . Educação e Atualidade Brasileira. São Paulo: Cortez; IPF, 2002b. . Educação Como Prática da Liberdade. Rio de Janeiro: Paz e Terra, 2002c. . Educação e Mudança. Rio de Janeiro: Paz e Terra, 2002d. . Pedagogia do Oprimido. Rio de Janeiro: Paz e Terra, 2002e. . Pedagogia da Esperança. São Paulo: Paz e Terra, $2002 \mathrm{f}$. . Professora Sim, Tia Não. São Paulo: Olho D’água, 2002g. 
GERALDI, J. W. Linguagem e Ensino: exercícios de militância e divulgação. Campinas, SP: Mercado de Letras, 2006.

HELLER, A. O Cotidiano e a História. 7 ed. Tradução Carlos Nelson Coutinho e Leandro Konder. São Paulo: Paz e Terra, 2004.

HORTON, M.; FREIRE, P. O caminho se faz caminhando: conversas sobre educação e mudança social. Tradução de Vera Lúcia M. Josceline. Petrópolis, RJ: Vozes, 2003.

MARSHALL, T. H. Cidadania, classe social e status.Tradução Meton Gadelha. Rio de Janeiro: Zahar, 1967.

MARX, K.; ENGELS, F. A Ideologia Alemã. Tradução Frank Muller. São Paulo: Martin Claret, 2005.

PITANO, S. C. Paulo Freire, Jürgen Habermas e o ideal formativo da educação popular: cidadão ou sujeito social? Curitiba, PR: CRV, 2016.

TORRES, C. A. Diálogo com Paulo Freire. Tradução Mônica Mattar Oliva. São Paulo: Loyola, 2001.

SANDRO de CASTRO PITANO: Doutor em Educação pela Universidade Federal do Rio Grande do Sul, pós-doutorado pelo Programa de Pós- Graduação em Educação da UNISINOS. Professor do Instituto de Ciências Humanas da Universidade Federal de Pelotas (UFPel).

E-mail: scpitano@smail.com 